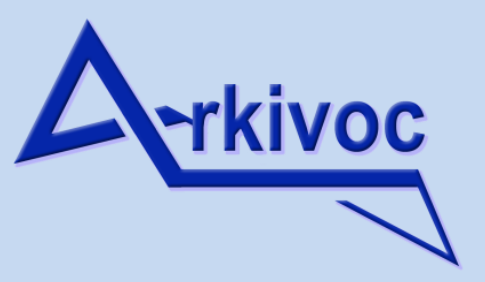

Free to Authors and Readers
A Platinum Open Access Journal for Organic Chemistry

\section{Review}

Arkivoc 2021, part v, 24-40

\title{
Use of oxygenated 1,3-dipoles for the synthesis of nitrogen containing heterocycles
}

\author{
Albert Padwa \\ Department of Chemistry, Emory University, Atlanta, GA, 303222 \\ E-mail: chemap@emory.edu
}

Dedicated to Peter Jacobi on the occasion of his retirement from Dartmouth College and in recognition of his many outstanding contributions to heterocyclic chemistry

Received 09-23-2020

Accepted $10-22-2020$

Published on line 10-31-2020

\begin{abstract}
Over the past several decades, the 1,3-dipolar cycloaddition reaction has been successfully applied in alkaloid synthesis as a strategy to reduce the number of steps, increase overall yield and employ more easily available starting materials. This mini-review presents selected examples making use of substituted carbonyl ylides as 1,3-dipoles for the preparation of numerous nitrogenous natural products. The cycloaddition reactions of mesoionic oxazolium ylides (isomünchnones) are first discussed, wherein intramolecular reactions of these dipoles have been exploited as an approach to the ring system of several different alkaloids. The creation of carbonyl ylide dipoles from the reaction of $\alpha$-diazo compounds with either ketones, esters or amides in the presence of $\mathrm{Rh}$ (II) catalysts has significantly broadened their applicability for natural product synthesis and is reviewed here. The cases presented demonstrate that a domino cascade strategy of these unique 'push-pull' dipoles may play a major role in shaping the future synthesis of complex nitrogen-containing natural products.
\end{abstract}

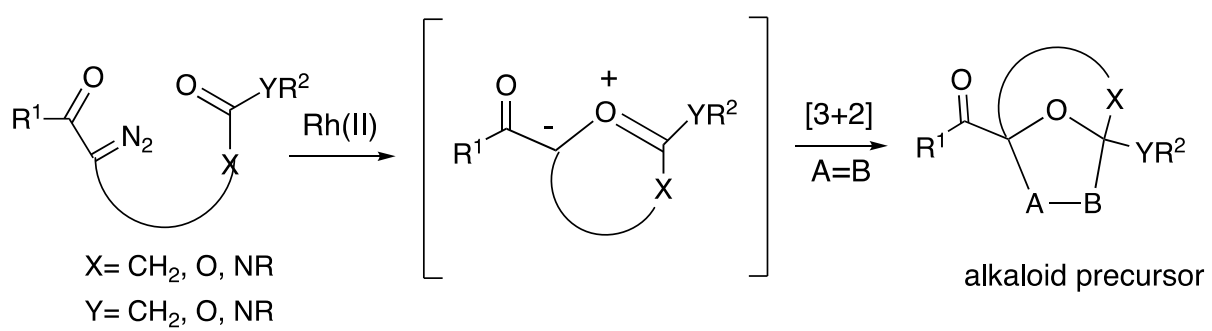

Keywords: 1,3-Dipoles; cycloaddition; carbonyl ylides; mesoionic systems; rhodium(ii) catalysis; diazoalkanes; alkaloid synthesis 


\section{Table of Contents}

1. Introduction

2. Carbonyl Ylides via Rh(II)-Catalysis of Diazo Compounds

3. Mesoionic Carbonyl Ylide Systems

3.1. Tandem cyclization/cycloaddition/cationic $\pi$-cyclization protocol

3.2. Approach to the quinoline ring system of the ergot alkaloids

3.3. ( \pm )-Vallesamidine

3.4. ( \pm )-Lycopodine

3.5. Indolizidine alkaloids

3.6. Mappicine ketone

3.7. ( \pm )-Camptothecin

3.8. (+)-Tashiromine

3.9. Atorvastatin

4. 'Push-Pull' Carbonyl Ylide Systems

4.1. ( \pm )-Aspidophytine

4.2. Kopsifoline alkaloids

4.3. ( \pm )-3H-Epivincamine and $( \pm)$-tacamonine

4.4. (-)-Vindoline

5. Conclusions

6. Acknowledgements

References

\section{Introduction}

In 1960 Rolf Huisgen introduced the concept of 1,3-dipolar cycloadditions providing five-membered ring heterocycles. ${ }^{1}$ In subsequent studies, his research team demonstrated that the $(3+2)$ cycloaddition of a variety of 1,3-dipoles with alkenes, alkynes, and heteroatom-containing dipolarophiles provided a broad spectrum of nitrogen heterocycles. ${ }^{1}$ The rate and regioselectivity of the cycloaddition has been rationalized through FMO analysis. $^{2-4}$ These dipolar cycloadditions are also extremely useful for the synthesis of natural products such as alkaloids and other biologically important structures employing rather simple starting materials. In addition, dipolar cycloadditions using chiral substrates for asymmetric synthesis has been extensively explored since the 1990s. 5 Because several reviews and related articles have been published dealing with the synthetic aspects of dipolar cycloaddition chemistry for the preparation of natural products, 6,7 this mini-review acknowledging the many contributions made by Peter Jacobi is intended to provide a selective rather than an exhaustive survey of the use of carbonyl ylide dipoles for alkaloid synthesis.

\section{Carbonyl Ylides via Rh(II)-Catalysis of Diazo Compounds}

The creation of carbonyl ylide dipoles from the reaction of $\alpha$-diazo compounds with ketones in the presence of $\mathrm{Rh}$ (II) catalysts (Scheme 1) ${ }^{8-13}$ has significantly broadened their applicability for natural product synthesis. ${ }^{14-16}$ 
The ease of generating the dipole, the rapid accumulation of polyfunctionality in a relatively small molecular framework, the high stereochemical control of the subsequent [3+2]-cycloaddition, and the fair predictability of its regiochemistry, have contributed to the popularity of the reaction. 17,18 When the reacting components are themselves cyclic or have ring substituents, complex multicyclic arrays, such as those contained in drugs and natural products, can be constructed in a single step.

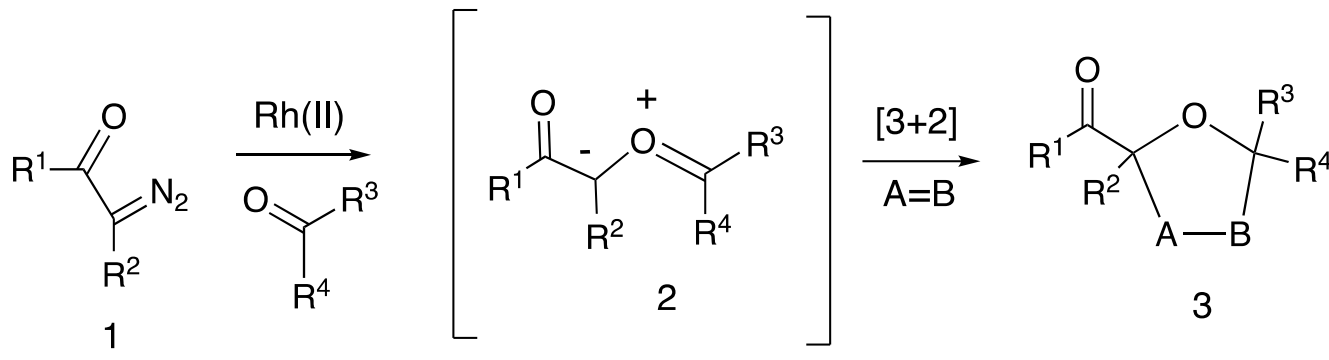

\section{Scheme 1}

\section{Mesoionic Carbonyl Ylide Systems}

Mesoionic oxazolium ylides (isomünchnones) correspond to the cyclic equivalent of a carbonyl ylide embedded in a heteroaromatic ring and these reactive intermediates readily undergo 1,3-dipolar cycloaddition with suitable dipolarophiles. Isomünchnones are readily obtained through the transition metal catalyzed cyclization of a suitable $\alpha$-diazoimide precursor. ${ }^{19}$ The starting diazoimides are easily constructed by acetoacylation $^{20}$ or malonylacylation ${ }^{21}$ of the corresponding amides which are then subjected to standard diazo transfer techniques. ${ }^{22}$ The first successful preparation and isolation of an isomünchnone induced by a transition metal process was described in $1974 .{ }^{23}$ Heating a sample of diazoimide $4\left(R^{1}\right.$ and $R^{3}=$ aryl, $R^{2}=$ methyl) in the presence of a catalytic amount of $\mathrm{Cu}_{2}(\mathrm{acac})_{2}$ afforded a red crystalline material which precipitated from the reaction mixture (Scheme 2). The red solid was assigned as isomünchnone $\mathbf{5}$ on the basis of its spectral data and elemental analysis. Mesoionic ylide $\mathbf{5}$ was found to be air stable for several weeks and its overall stability was attributed to its dipolar aromatic resonance structure. Formation of the isomünchnone ring can be rationalized by initial generation of a metallo-carbenoid species which is then followed by intramolecular cyclization onto the neighboring carbonyl oxygen to form the mesoionic dipole. ${ }^{24}$ These reactive dipoles can then be trapped with a variety of dipolarophiles to give cycloadducts in high yield.

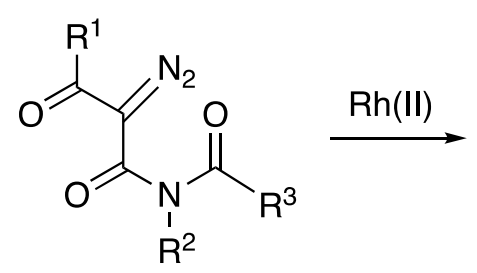

$4 ; \mathrm{R}^{1}=\mathrm{R}^{3}=$ aryl; $\mathrm{R}^{2}=\mathrm{CH}_{3}$<smiles>[R7]C(=O)C1=[O+]C([R3])=C(C)C1=O</smiles>

5a<smiles>[R7]C(=O)c1oc([R])[n+]([R7])c1OC</smiles>

$5 b$

\section{Scheme 2}




\subsection{Tandem cyclization/cycloaddition/cationic $\pi$-cyclization protocol}

Interesting examples of 1,3-dipolar cycloadditions of isomünchnones possessing an unactivated alkene have been reported to give rise to complex azapolycyclic compounds in one step. $25-27$ The 1,3-dipolar cycloaddition of isomünchnones derived from $\alpha$-diazoimides of type 6 provides a uniquely functionalized cycloadduct (i.e. 7) containing a 'masked' $\mathrm{N}$-acyliminium ion (Scheme 3). 28 By incorporating an internal nucleophile on the tether, annulation of the original dipolar cycloadduct $\mathbf{7}$ would allow the construction of a more complex nitrogen heterocyclic system, particularly B-ring homologs of the erythrinane family of alkaloids. By starting from simple acyclic diazoimides 6, a tandem cyclization cycloaddition cationic $\pi$-cyclization protocol was established as a method for the construction of complex nitrogen polyheterocycles of type $\mathbf{8}$.

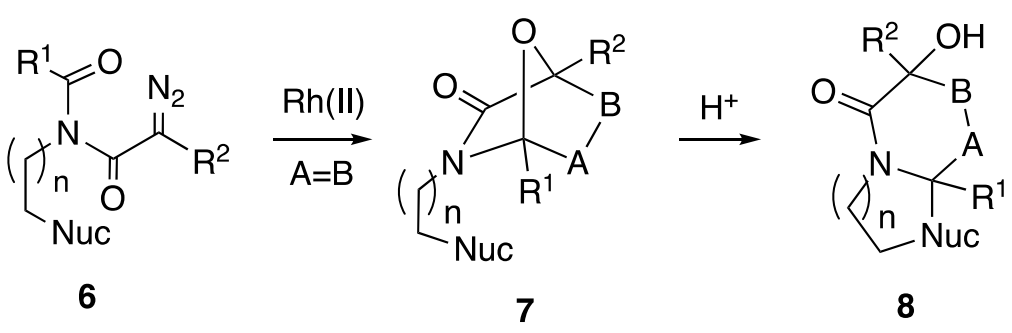

\section{Scheme 3}

\subsection{Approach to the quinoline ring system of the ergot alkaloids}

A number of approaches to complex alkaloids have been reported in which the intramolecular cycloaddition reactions of a transient isomünchnone dipole feature as the pivotal step for assembling the polycyclic frameworks. Thus, intramolecular reactions of isomünchnone dipoles generated from a series of alkenyl- and alkynyl-substituted diazoimides have been exploited as an approach to the quinoline ring system (rings $\mathrm{C}$ and D) of the ergot alkaloids (e.g., lysergic acid, 12). In one example, the $\mathrm{Rh}_{2}(\mathrm{OAc})_{4}$-mediated tandem cyclization/cycloaddition sequence from diazoimide $\mathbf{9}$ led to cycloadduct $\mathbf{1 0}$ in very good yield (Scheme 4). ${ }^{28}$ The polycyclic adduct $\mathbf{1 0}$ was readily elaborated to $\mathbf{1 1}$ en route to ergot alkaloids via $\mathrm{BF}_{3}$.OEt 2 -mediated ether bridge cleavage and a Barton/McCombie deoxygenation sequence. Further attempts toward lysergic acid $\mathbf{1 2}$ were, however, thwarted due to the inability to isomerize the trisubstituted double bond in $\mathbf{1 1 .}$ 


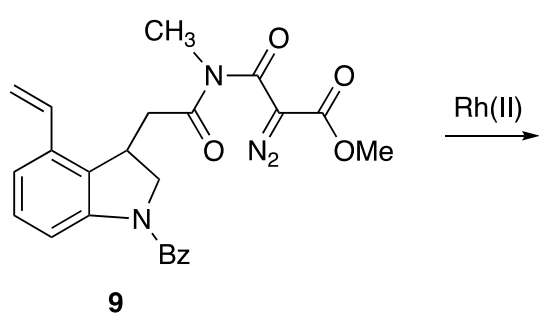

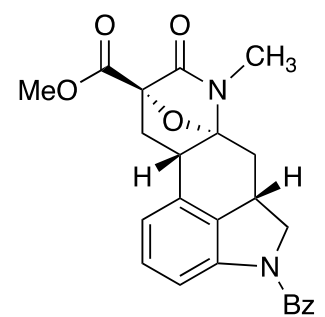

$10 ; 93 \%$

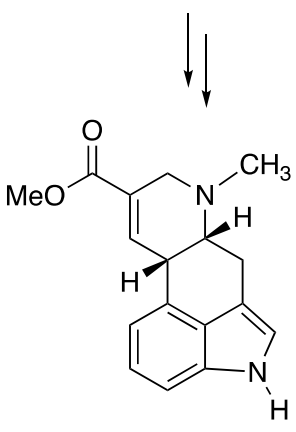

11

\section{Scheme 4}

\section{3. ( \pm )-Vallesamidine}

Given the success in forming novel azabicyclic systems derived from an intramolecular isomünchnone cycloaddition/ $\mathrm{N}$-acyliminium ion cyclization sequence, this domino strategy was also used for a formal synthesis of vallesamidine 18 via the key Heathcock intermediate 17 (Scheme 5). 29,30<smiles>CCOC(=O)C(=O)N1CCCC(CC)(CC/C=C\c2ccccc2[N+](=O)[O-])C1=O</smiles>

13<smiles></smiles>

$14 ; 79 \%$<smiles>CCC12CCCN3C(=O)C[C@H](c4ccccc4[N+](=O)[O-])C(=C31)C2</smiles>

17<smiles>CCOC(=O)C1(O)C(=O)N2CCCC3(CC)CCC(=C23)[C@H]1c1ccccc1[N+](=O)[O-]</smiles>

15

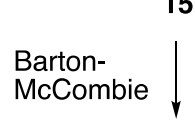<smiles>CCOC(=O)[C@H]1C(=O)N2CCC[C@]3(CC)CCC(=C23)[C@H]1c1ccccc1[N+](=O)[O-]</smiles>

16

\section{Scheme 5}


Thus, $\mathrm{N}$-malonylacylation of the precursor amide was carried out followed by a standard diazo transfer reaction to produce the requisite $\alpha$-diazoimide 13. The reaction of $\mathbf{1 3}$ with a $\mathrm{Rh}$ (II)-catalyst gave cycloadduct 14, which underwent a TMSOTf catalyzed ring opening to furnish enamide 15 in $78 \%$ yield. With the ringopened lactam in hand, a Barton-McCombie deoxygenation reaction ${ }^{31}$ delivered 16 in $88 \%$ yield. Utilization of a sequential saponification/decarboxylation protocol afforded enamide 17.32 This sequence constitutes a formal synthesis of ( \pm )-vallesamidine 18, based on the successful conversion of $\mathbf{1 7}$ into $\mathbf{1 8}$ by Heathcock and co-workers. 30

\section{4. ( \pm )-Lycopodine}

Another application of the domino cascade process toward the construction of alkaloids involved the synthesis of ( \pm )-lycopodine $\mathbf{2 3}$ (Scheme 6). 33 The isomünchnone cycloadduct $\mathbf{2 0}$ was formed from the Rh(II)-catalyzed reaction of diazo imide 19 and was found to be the precursor of the key Stork intermediate 22 (via 21). Formation of $\mathbf{2 2}$ from $\mathbf{2 1}$ occurred by way of a Pictet-Spengler cyclization of the $\mathrm{N}$-acyliminium ion derived from 20. Central to this strategy was the expectation that the bicyclic iminium ion originating from $\mathbf{2 0}$ would exist in a chairlike conformation. ${ }^{33-35}$ Indeed, cyclization of the aromatic ring onto the $\mathrm{N}$-acyliminium ion center readily occurred from the axial position. ${ }^{36-38}$ The rearranged product $\mathbf{2 1}$ was then converted into the key intermediate $\mathbf{2 2}$ previously used by Stork for the synthesis of ( \pm )-lycopodine $\mathbf{2 3 .}{ }^{33}$

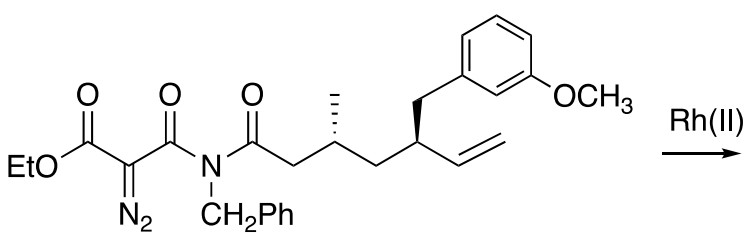

19

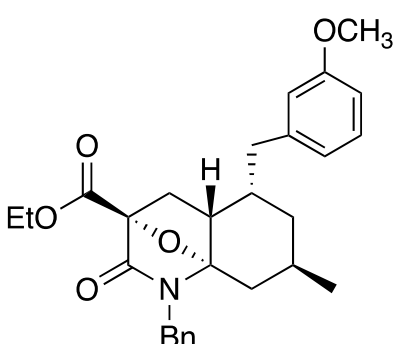

20

$\mathrm{BF}_{3} / \mathrm{AcOH}$

$\checkmark$

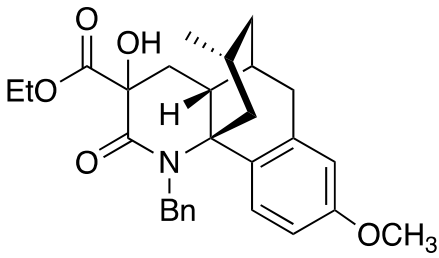

21

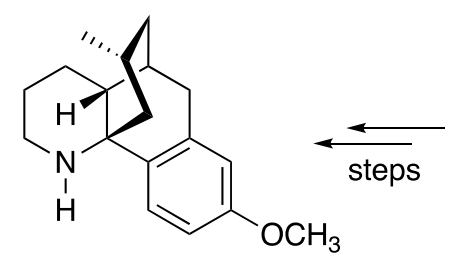

22

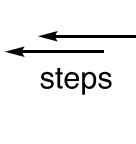

( \pm -lycopodine; 23

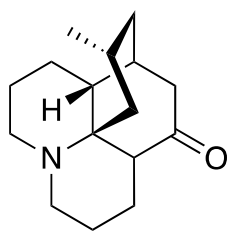

.

\section{Scheme 6}

\subsection{Indolizidine alkaloids}

A further implementation of the cascade methodology involves the efficient assembly of the indolizidine ring system by using the $\mathrm{Rh}(\mathrm{II})$-catalyzed [3+2]-dipolar cycloaddition of the phenylsulfonyl substituted diazopyrrolidinone $\mathbf{2 4}$ with an appropriately substituted dipolarophile (Scheme 7). The resulting pyridone 27 represents a very versatile synthon. As depicted in below, structural manipulation of the pyridinone ring and subsequent functional group interconversions provides access to several indolizidine alkaloids. ${ }^{39-42}$ The $C_{6}$ 
hydroxyl substituent, protected as triflate 28, allows for an assortment of cross coupling-possibilities. The versatility of the method was demonstrated by the synthesis of the angiotensin converting enzyme inhibitor (-)-A58365A 29, ( \pm )-ipalbidine 30, $\beta$-carbolinone 31 and a variety of other novel indolizidine-based compounds. 42

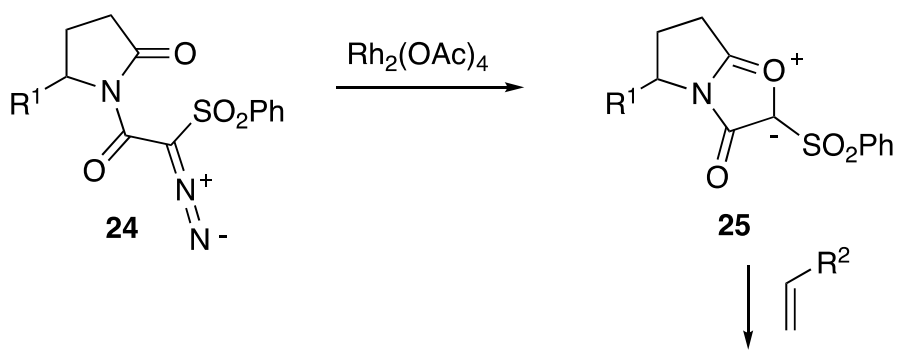

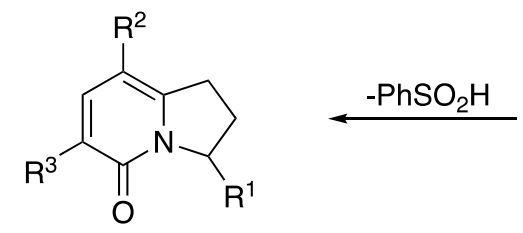

27; $\mathrm{R}^{3}=\mathrm{OH}$

28; $R^{3}=$ OTf

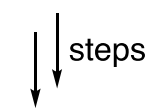<smiles>O=C(O)CCc1cc(O)c2n(c1=O)C(C(=O)O)CC2</smiles>

Ace Inhibitor; 29 A58365A<smiles>CC1=C(Br)CN2CCCC2C1</smiles>

$\mathrm{Ar}=p-\mathrm{HOC}_{6} \mathrm{H}_{4}$ ipalbidine; 30<smiles>[R]C1CC2(S(=O)(=O)O)CCC([R])N2C1=O</smiles>

26<smiles>[R2]c1c2n(c(=O)c3[nH]c4ccccc4c13)CCC2</smiles>

$\beta$-carbolinone core; 31

\section{Scheme 7}

\subsection{Mappicine ketone}

An efficient synthesis of the naturally occurring oxoindolizino quinoline mappicine ketone $\mathbf{3 7}$ has been carried out by Greene and coworkers by making use of pyridone 32a as a key intermediate.43 The synthesis of $\mathbf{3 7}$ began with formation of the known cycloadduct $32 \mathrm{a}\left(\mathrm{R}_{1}=\mathrm{H} ; \mathrm{R}_{2}=\mathrm{CO}_{2} \mathrm{Me}\right)$ by cycloaddition of the isomünchnone dipole derived from diazo sulfone $\mathbf{2 4}$ with methyl acrylate (Scheme 8). 39 This multistep sequence proceeded smoothly and in high yield when catalyzed by rhodium(II) acetate. Hot aqueous hydrobromic acid then effected decarbomethoxylation of $\mathbf{3 2 a}$ to give $\mathbf{3 2} \mathbf{b}$ in $\mathbf{8 2} \%$ yield. Etherification of $\mathbf{3 2} \mathbf{b}$ with commercially available (E)-1-bromo-2-pentene and cesium carbonate in dimethylformamide produced the expected substitution product 32c, which cleanly underwent a Claisen rearrangement in refluxing chlorobenzene to afford the desired rearranged derivative 33 in $74 \%$ overall yield. This transformation is a rare example of a Claisen rearrangement taking place in a hydroxypyridone system. 44,45 The $\alpha$-hydroxypyridone 33 was then converted into its triflate derivative under standard conditions. This was followed by Stille coupling with tetramethyltin to provide $\alpha$-methyl pyridone 34 in $84 \%$ yield. In the presence of rhodium(III) chloride in hot ethanol, compound 34 was rapidly isomerized to olefin $35 \mathrm{a}$ (91\%). The success of this key 
transformation derives from the carbon symmetry of the $\beta$-substituent in pyridone 34 . Oxidation of 35a in two steps then selectively generated the Friedländer substrate $\mathbf{3 5 b}$, which was reacted with o-aminobenzaldehyde to give oxoindolizino-quinoline 36 in $73 \%$ yield. Ozonolysis of 36 in $\mathrm{CH}_{2} \mathrm{Cl}_{2} / \mathrm{MeOH}$ at $-78{ }^{\circ} \mathrm{C}$ accomplished selective double-bond cleavage in $\mathbf{3 6}$ to provide mappicine ketone $\mathbf{3 7}$.<smiles>[N-]=[N+]=C(C(=O)N1CCCC1=O)[SnH]1Oc2ccccc21</smiles>

$24 \stackrel{N}{N}-$<smiles>[R]c1cc(O[Tl])c(=O)n2c1CCC2</smiles>

32a; $\mathrm{R}^{1}=\mathrm{H} ; \mathrm{R}^{2}=\mathrm{CO}_{2} \mathrm{Me}$

32b; $R^{1}=R^{2}=H$

32c; $\mathrm{R}^{1}=\mathrm{CH}_{2}=\mathrm{CHC}_{2} \mathrm{H}_{5} ; \mathrm{R}^{2}=\mathrm{H}$<smiles>C=CC(CC)c1cc2n(c(=O)c1O)CCC2</smiles>

$\mathrm{PhNTf}_{2}$ $\left(\mathrm{CH}_{3}\right)_{4} \mathrm{Sn}, \mathrm{Pd}(0)$

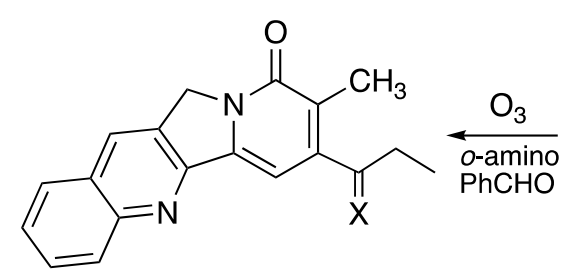

36; $\mathrm{X}=\mathrm{CHCH}_{3}$ 37; $X=O$; mappicine ketone $(60 \%)$

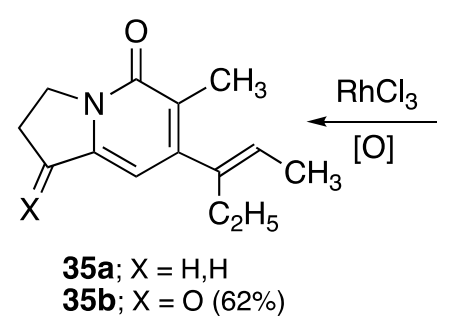<smiles>C=CC(C)c1cc2n(c(=O)c1C)CCC2</smiles>

35b; $X=O(62 \%)$

\section{Scheme 8}

\section{7. ( \pm )-Camptothecin}

A related synthesis of racemic camptothecin $\mathbf{3 8}$ was also carried out by Greene and coworkers soon thereafter and is similarly based on the isomünchnone dipole strategy. 46 The starting point commenced from the readily available hydroxyl-pyridone 32b (Scheme 9). Subsequent steps include a Claisen rearrangement of a functionalized allylic ether, a hindered Heck coupling, and a Friedländer condensation.<smiles>[N-]=[N+]=C(C(=O)N1CCCC1=O)c1ccccc1</smiles>

24

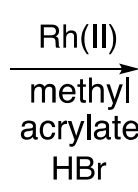

$\mathrm{HBr}$<smiles>C#CC(C)C</smiles>

32b<smiles>C[C@]1(O)C(=O)OCc2c1cc1n(c2=O)Cc2cc3ccccc3nc2-1</smiles>

( \pm -camptothecin; 38

\section{Scheme 9}

\section{8. (+)-Tashiromine}

Suga and coworkers have reported on a highly enantioselective 1,3-dipolar cycloaddition reaction between several 3-(2-alkenoyl)-2-oxazolidinones and isomünchnone ylides that were generated from the $\mathrm{Rh}(\mathrm{II})$ catalyzed reaction of $\mathrm{N}$-diazoacetyl lactams. $47 \mathrm{~N}$-Diazoacetyl lactams that possess 5-, 6-, and 7-membered rings were transformed to the corresponding epoxy-bridged indolizidines, quinolizidines, and 1-azabicyclo[5.4.0] undecanes (41) with good to high enantioselectivities according to this method. A regio- and 
stereoselective ring-opening of the epoxy-bridged indolizidine cycloadduct $\mathbf{4 1}$ gave the corresponding alcohol as a single diastereomer. The sequence of an asymmetric cycloaddition reaction followed by ring-opening was applied to the syntheses of several chiral indolizidine derivatives, including (+)-tashiromine (43) (Scheme 10).
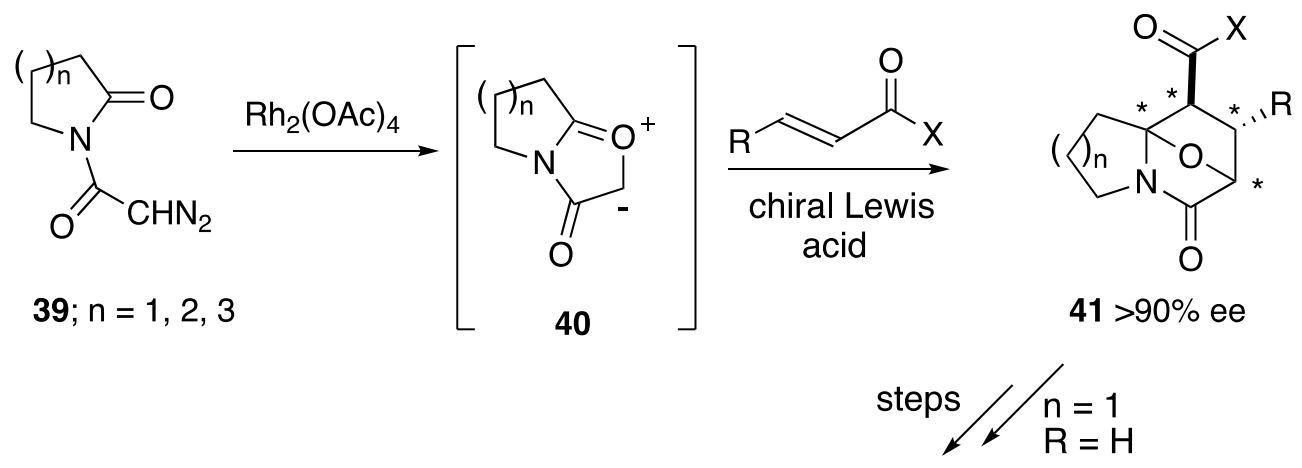

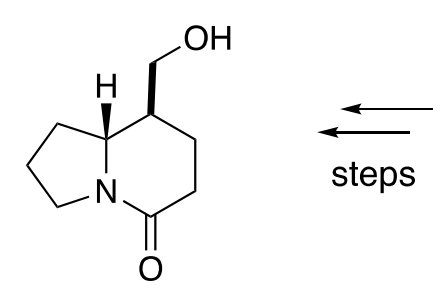

43; (+)-tashiromine<smiles>O=C(O)C1CC(O)C(=O)N2CCC[C@H]12</smiles>

42

\section{Scheme 10}

\subsection{Atorvastatin}

The well known pharmaceutical drug Atorvastatin, marketed under the trade name Lipitor, is a member of the drug class known as statins, which are used primarily for lowering blood cholesterol and for prevention of events associated with cardiovascular disease. Since Atorvastatin (46) is one of the top selling pharmaceuticals, it has been the subject of many synthetic studies aimed to improve its preparation, particularly the pyrrole core and pendant chiral diol. Gribble and Lopchik described the preparation of $\mathbf{4 6}$ in seven steps from commercially available 4-fluorophenylacetic acid. 48 The key step involved a 1,3-dipolar cycloaddition of the complex münchnone mesoionic heterocycle 45 with N,3-diphenylpropiolamide as shown in Scheme 11.49,50
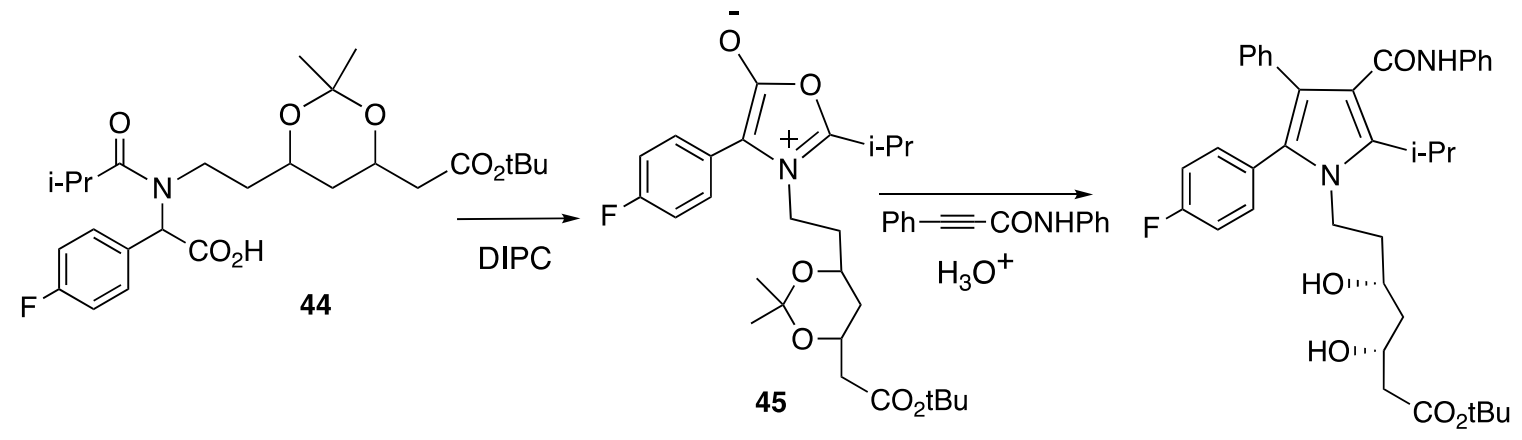

46; Atorvastatin

\section{Scheme 11}




\section{4. 'Push-Pull' Carbonyl Ylide Systems}

\section{1. ( \pm )-Aspidophytine}

One of the early examples of the trapping of a non-heteroaromatic carbonyl ylide dipole with a tethered $\pi$ bond for alkaloid synthesis was found as the central step in an approach toward the complex pentacyclic alkaloid ( \pm )-aspidophytine 51.51,52] The key sequence of reactions involved a 1,3-dipolar cycloaddition of the 'push-pull' dipole 48 across the indole $\pi$-system. The exo-cycloadduct $\mathbf{4 9}$ was the exclusive product isolated from the Rh(II)-catalyzed reaction of $\mathbf{4 7}$ (Scheme 12). It was assumed that in this case, the bulky tert-butyl ester functionality blocks the endo approach thereby resulting in cycloaddition taking place from the lesscongested exo face. Treatment of the resulting dipolar cycloadduct 49 with BF3.OEt2 induces a domino fragmentation cascade. The reaction proceeds by an initial cleavage of the oxabicyclic ring and formation of a transient $N$-acyliminium ion, which reacts further with the adjacent tert-butyl ester and sets the required lactone ring present in aspidophytine. A three-step sequence was then used to remove both the ester and $\mathrm{OH}$ groups from lactone 50. Subsequent functional group manipulations allowed for the high-yielding conversion of $\mathbf{5 0}$ into ( \pm )-aspidophytine $\mathbf{5 1 .}$
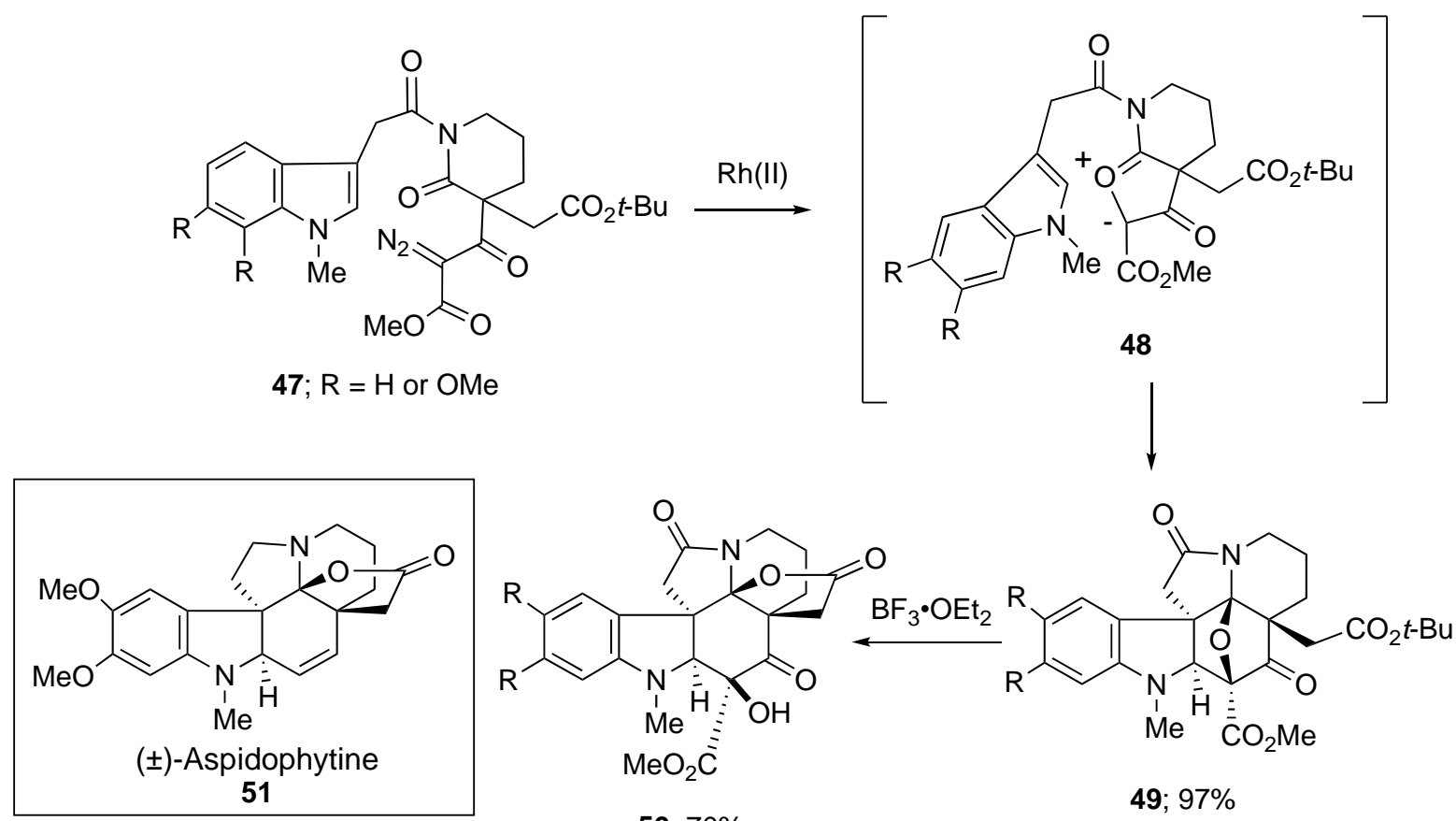

$50 ; 70 \%$

$49 ; 97 \%$

\section{Scheme 12}

\subsection{Kopsifoline alkaloids}

As a further extension of 'push-pull' dipole cycloaddition chemistry, the Rh(II)-catalyzed cyclization / cycloaddition cascade was applied toward the hexacyclic framework of the kopsifoline alkaloids. Using the metal-catalyzed domino reaction as a key step, the heterocyclic skeleton of the kopsifolines (52) could eventually be built by a 1,3-dipolar cycloaddition of a 'push-pull' carbonyl ylide dipole derived from $\alpha$-diazo ketoester $\mathbf{5 3}$ across the indole $\pi$-bond. Ring-opening of the resulting cycloadduct $\mathbf{5 4}$ followed by a reductive dehydroxylation step produced the critical silyl enol ether $\mathbf{5 5}$ necessary for the final F-ring closure. The facility and stereoselectivity of the key cycloaddition reaction was investigated in more detail using some model 
substrates. It was found that the heterocyclic skeleton of the kopsifoline alkaloid family $\mathbf{5 2}$ could readily be constructed by the proposed sequence of reactions outlined in Scheme 13.53,54 The isolation of $\mathbf{5 4}$ as a single diastereomer was rationalized by recognizing that the indole moiety approaches the dipole from the least sterically encumbered position. Ring-opening of the resulting cycloadduct $\mathbf{5 4}$ followed by a reductive dehydroxylation step resulted in the formation of the silyl enol ether $\mathbf{5 5}$ necessary for the final F-ring closure of the kopsifoline skeleton (i.e., formation of 56).

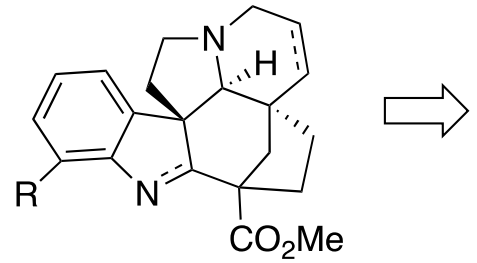

Kopsifoline framework (52) $\mathrm{R}=\mathrm{H}$ or OMe

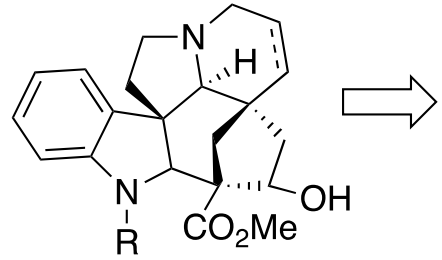

56

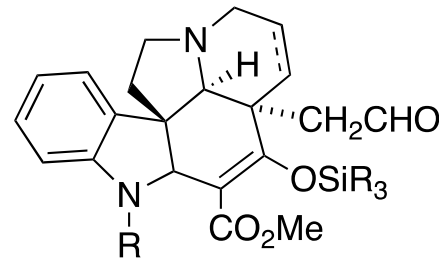

55

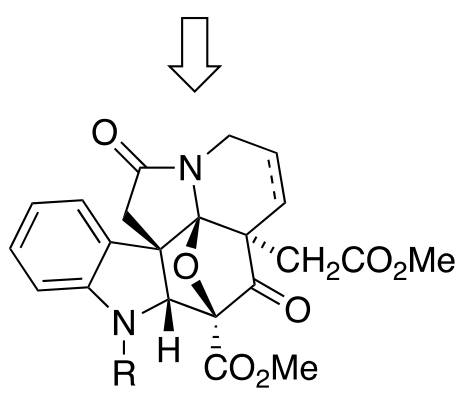

54

\section{Scheme 13}

\section{3. ( \pm )-3H-Epivincamine and ( \pm )-tacamonine}

The total synthesis of several members of the vinca and tacaman class of indole alkaloids has also been accomplished using 'push-pull' dipoles in the critical cycloaddition step.55,56 The central step in the synthesis consists of an intramolecular [3+2]-cycloaddition reaction of $\alpha$-diazo indoloamide 57, which delivers the pentacyclic skeleton of the natural product in excellent yield (Scheme 14).<smiles>[R]C(=C)CC([R])C(=O)N1CCc2c(n(C(=O)C(=N)OCC)c3ccccc23)C1=O</smiles>
57

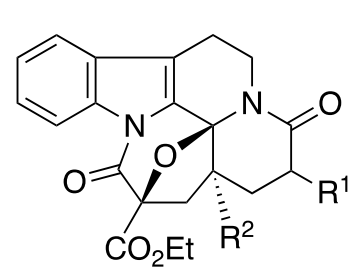

58; $R^{1}=E t ; H ; 95 \%$ 59; $\mathrm{R}^{2}=\mathrm{Et} ; \mathrm{H} ; 90 \%$

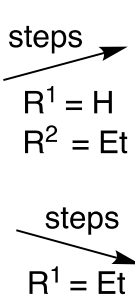

$\mathrm{R}^{2}=\mathrm{H}$<smiles>CC[C@H]1CN2CCc3c4n(c5ccccc35)C(=O)C[C@H](C2)[C@H]4[C@H]1C</smiles>

61; (土)-tacamonine

\section{Scheme 14}


The acid lability of the oxabicyclic structure was exploited to establish the trans-D/E-ring fusion of $( \pm)-3 \mathrm{H}$ epivincamine 60 . Finally, a base induced ketoamide ring contraction was utilized to generate the E-ring of the natural product. A variation of the cascade sequence of reactions used to synthesize ( \pm )-3H-epivincamine $\mathbf{6 0}$ was also employed for the synthesis of the tacaman alkaloid ( \pm )-tacamonine $6 \mathbf{6}$.

\section{4. (-)-Vindoline}

Even though the Boger group's synthesis of the Vinca alkaloid family does not involve a Rh-carbenoid intermediate, their approach proceeds through a related 'push-pull' dipole intermediate and is based on an intramolecular $[4+2] /[3+2]$-cycloaddition reaction of a 1,3,4-oxadiazole heterocycle. ${ }^{57-61}$ This unique domino cascade was used to assemble the fully functionalized pentacyclic ring system of vindoline 66 in a single step that forms four C-C bonds and three rings while introducing all the requisite functionality and setting all six stereocenters within the central ring including three contiguous and four total quaternary centers (Scheme 15). The reaction leading to 65 is initiated by an intramolecular inverse electron demand Diels-Alder cycloaddition of the 1,3,4-oxadiazole 62 with the tethered enol ether. Loss of nitrogen from the initial Diels-Alder cycloadduct 63 provides the 'push-pull' carbonyl ylide 64, which then undergoes a subsequent 1,3-dipolar cycloaddition with the tethered indole. Importantly, the diene and dienophile substituents complement and reinforce the [4+2]-cycloaddition regioselectivity dictated by the linking tether. The relative stereochemistry in the cycloadduct is controlled by a combination of (1) the dienophile geometry and (2) an exclusive endo indole [3+2]-cycloaddition sterically directed to the R-face opposite the newly formed fused lactam. This endo diastereoselection for the 1,3-dipolar cycloaddition has been attributed to a conformational (strain) preference dictated by the dipolarophile tether. 59 Cycloadduct 65 was eventually transformed into the natural product vindoline $\mathbf{6 6}$ in several additional steps. Extension of these cascade studies by the Boger group also provided for a total synthesis of the bis-indole alkaloids vinblastine and vincristine. 61

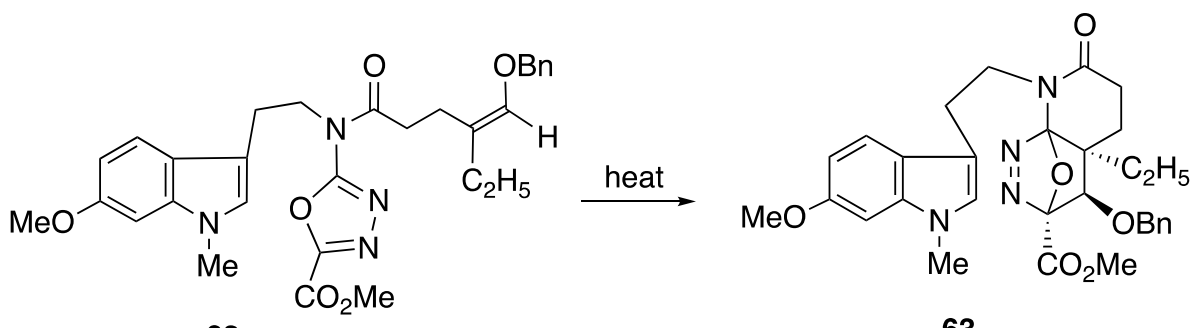

62

63<smiles>[V]C1CCCCC1</smiles>

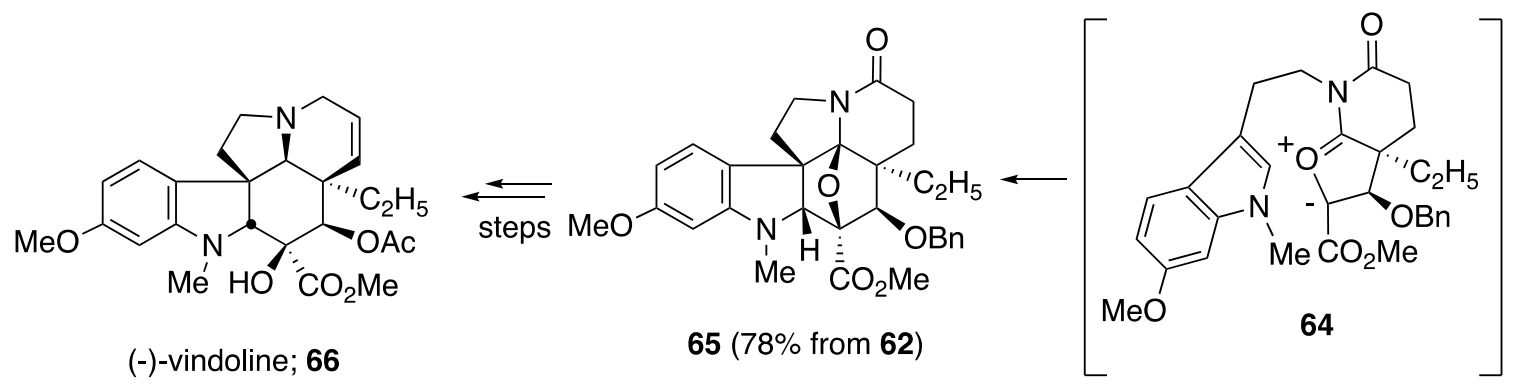

\section{Scheme 15}




\section{Conclusions}

The application of the cycloaddition of carbonyl ylide dipoles for the synthesis of alkaloids as described in this mini-review spans a broad spectrum of organic chemistry. The regio- and stereoselectivity of the 3+2cycloaddition reaction is now well established, making it an attractive strategic disconnection for synthetic design of various nitrogenous natural products. As is the case in all new areas of research, future investigations of the chemistry of these dipolar cycloadditions of carbonyl ylides for heterocyclic synthesis will be dominated by the search for new asymmetric processes. Future developments will also depend on gaining a greater understanding of the mechanistic details of this fascinating and synthetically important process.

\section{Acknowledgments}

AP is particularly grateful to the National Science Foundation, the National Institute of Health and the Camille and Henry Dreyfus Foundation for generous financial support over his career.

\section{References}

1. Synthetic Applications of 1,3-Dipolar Cycloaddition Chemistry Towards Heterocycles and Natural Products, Padwa, A.; Pearson, W. H. Wiley-Interscience: Hoboken, NJ, 2003.

2. Huisgen, R. Angew. Chem., Int. Ed., 1963, 2, 565-632.

https://doi.org/10.1002/anie.196305651

3. Huisgen, R. 1,3-Dipolar Cycloaddition Chemistry, Padwa, A.; Ed., Vol. 1, Wiley-Interscience: New York, NY, 1984, p1-176.

4. Houk, K. N.; Yamaguchi, K. in 1,3-Dipolar Cycloaddition Chemistry, Padwa, A. Ed., Vol. 2, Wiley-Interscience: New York, NY, 1984, p407-450.

5. Suga, H.; Itoh, K. in Methods and Applications of Cycloaddition Reactions in Organic Syntheses, Nishiwaki, N. Ed.; Wiley-Interscience: Hoboken, NJ, 2014, p175-204.

6. Nair, V.; Suja, T. D. Tetrahedron 2007, 63, 12247-12275.

https://doi.org/10.1016/i.tet.2007.09.065

7. Hodgson, D. M.; Labande, A. H.; Muthusamy, S. Org. React. 2013, 80, 133-157. https://doi.org/10.1002/0471264180.or080.02

8. Doyle, M. P.; McKervey, M. A.; Ye, T. Modern Catalytic Methods for Organic Synthesis with Diazo Compounds: from Cyclopropanes to Ylides, Wiley: New York, NY, 1995.

9. Doyle, M. P. Chem. Rev. 1986, 86, 919-939.

https://doi.org/10.1021/cr00075a013

10. Ye, T.; McKervey, M. A. Chem. Rev. 1994, 94, 1091-1160.

https://doi.org/10.1021/cr00028a010

11. Padwa, A.; Hornbuckle, S. F. Chem. Rev. 1991, 91, 263-309.

https://doi.org/10.1021/cr00003a001

12. Padwa, A.; Krumpe, K. E. Tetrahedron 1992, 48, 5385-5453.

https://doi.org/10.1016/S0040-4020(01)88298-3 
13. Padwa, A.; Weingarten, M. D. Chem. Rev. 1996, 96, 223-270. https://doi.org/10.1021/cr950022h

14. Padwa, A.; Curtis, E. A.; Sandanayaka, V. P. J. Org. Chem. 1997, 62, 1317-1325. https://doi.org/10.1021/jo961574i

15. Dauben, W. G.; Dinges, J.; Smith, T. C. J. Org. Chem. 1993, 58, 7635-7637. https://doi.org/10.1021/jo00079a004

16. Koyama, H.; Ball, R. G.; Berger, G. D. Tetrahedron Lett. 1994, 35, 9185-9188. https://doi.org/10.1016/0040-4039(94)88460-9

17. Padwa, A. Angew. Chem., Int. Ed. Engl. 1976, 15, 123-136. https://doi.org/10.1002/anie.197601231

18. Mehta, G.; Muthusam, M. S. Tetrahedron 2002, 58, 9477-9504. https://doi.org/10.1016/S0040-4020(02)01187-0

19. Osterhout, M. H.; Nadler, W. R.; Padwa, A. Synthesis 1994, 26, 123-141. https://doi.org/10.1055/s-1994-25420

20. Doyle, M. P.; Dorow, R. L.; Terpstra, J. W.; Rodenhouse, R. A. J. Org. Chem. 1985, 50, 1663-1666. https://doi.org/10.1021/jo00210a020

21. Sato, M.; Kanuma, N.; Kato, T. Chem. Pharm. Bull. 1982, 30, 1315-1321. https://doi.org/10.1248/cpb.30.1315

22. Regitz, M. Chem. Ber. 1966, 99, 3128-3140. https://doi.org/10.1002/cber.19660991010

23. Hamaguchi, M.; Ibata, T. Tetrahedron Lett. 1974, 15, 4475-4476. https://doi.org/10.1016/S0040-4039(01)92194-X

24. Gillon, A.; Ovadia, D.; Kapon, M.; Bien, S. Tetrahedron 1982, 38, 1477-1484. https://doi.org/10.1016/0040-4020(82)80234-2

25. Padwa, A.; Hertzog, D. L.; Chinn, R. L. Tetrahedron Lett. 1989, 30, 4077-4080. https://doi.org/10.1016/S0040-4039(00)99326-2

26. Padwa, A.; Hertzog, D. L.; Nadler, W. R.; Osterhout, M. H.; Price, A. T. J. Org. Chem. 1994, 59, 1418-1427. https://doi.org/10.1021/jo00085a035

27. Maier, M. E.; Schoffling, M. B. Chem. Ber. 1989, 122, 1081-1094. https://doi.org/10.1002/cber.19891220613

28. Padwa, A.; Marino, Jr., J. P.; Osterhout, M. H. J. Org. Chem. 1995, 60, $2704-2713$. https://doi.org/10.1021/jo00114a017

29. Dickman, D. A.; Heathcock, C. H. J. Am. Chem. Soc. 1989, 111, 1528-1530. https://doi.org/10.1021/ja00186a074

30. Heathcock, C. H.; Norman, M. H.; Dickman, D. A. J. Org. Chem. 1990, 55, 798-811. https://doi.org/10.1021/jo00290a006

31. Barton, D. H. R.; McCombie, S. W. J. Chem. Soc., Perkin Trans. 1975, 1, 1574-1575. https://doi.org/10.1039/p19750001574

32. Padwa, A.; Harring, S. R.; Semones, M. A. J. Org. Chem. 1998, 63, 44-54. https://doi.org/10.1021/jo970847m

33. Stork, G.; Kretchmer, R. A.; Schlessinger, R. H. J. Am. Chem. Soc. 1968, 90, 1647-1648. https://doi.org/10.1021/ja01008a042

34. Ayer, W. A.; Bowman, W. R.; Joseph, T. C.; Smith, P. J. J. Am. Chem. Soc. 1968, 90, 1648-1650. 
https://doi.org/10.1021/ja01008a043

35. Heathcock, C. H.; Kleinman, E.; Binkley, E. S. J. Am. Chem. Soc. 1978, 100, 8036-8037. https://doi.org/10.1021/ja00493a057

36. Mondon, A.; Hansen, K. F.; Boehme, K.; Faro, H. P.; Nestler, H. J.; Vilhuber, H. J. ; Böttcher, K. Chem. Ber. 1970, 103, 615-638.

https://doi.org/10.1002/cber.19701030234

37. Mondon, A.; Seidel, P. R. Chem. Ber. 1971, 104, 2937-4959.

https://doi.org/10.1002/cber.19711040935

38. Mondon, A.; Nestler, H. J. Chem. Ber. 1979, 112, 1329-1347.

https://doi.org/10.1002/cber.19791120427

39. Sheehan, S. M.; Padwa, A. J. Org. Chem. 1997, 62, 438-439.

https://doi.org/10.1021/jo961690I

40. Straub, C. S.; Padwa, A. Org. Lett. 1999, 1, 83-85.

https://doi.org/10.1021/ol9905497

41. Padwa, A.; Sheehan, S. M.; Straub, C. S. J. Org. Chem. 1999, 64, 8648-8659.

https://doi.org/10.1021/jo9911600

42. Mmutlane, E. M.; Harris, J. M.; Padwa, A. J. Org. Chem. 2005, 70, 8055-8063. https://doi.org/10.1021/jo0511492

43. Raolji, G. B.; Garcon, S.; Greene, A. E.; Kanazawa, A. Angew. Chem., Int. Ed. 2003, 42, 5059-6061. https://doi.org/10.1002/anie.200352094

44. Jarvis, B. B.; Anderson, C. B. J. Heterocycl. Chem. 1983, 20, 471-473.

https://doi.org/10.1002/jhet.5570200243

45. Majumdar, K. C.; Kundu, A. K.; Chatterjee, P. J. Chem. Res. Synop. 1995, 386-387.

46. Anderson, R. J.; Raolji, G. B.; Kanazawa, A.; Greene, A. E. Org. Lett. 2005, 7, 2989-2991. https://doi.org/10.1021/ol0509641

47. Suga, H.; Hashimoto, Y.; Yasumura, S.; Takezawa, R.; Itoh, K.; Kakehi, A. J. Org. Chem. 2013, 78, 1084010852.

https://doi.org/10.1021/jo401837d

48. Lopchuk, J. M.; Gribble, G. W. Tetrahedron Lett. 2015, 56, 3208-3211.

https://doi.org/10.1016/i.tetlet.2014.12.104

49. Huisgen, R.; Gotthardt, H.; Bayer, H. O.; Schaefer, F. C. Angew. Chem., Int. Ed. 1964, 2, 136-137. https://doi.org/10.1002/anie.196401361

50. Reissig, H. ; Zimmer, U. R. Angew. Chem., Int. Ed. 2014, 53, 9708-9710.

https://doi.org/10.1002/anie.201405092

51. Mejiá-Oneto, J. M.; Padwa, A. Org. Lett. 8, 2006, 3275-3278.

https://doi.org/10.1021/ol061137i

52. Mejiá-Oneto, J. M.; Padwa, A. Helv. Chim. Acta. 2008, 91, 285-302.

https://doi.org/10.1002/hlca.200890034

53. Zhang, H.; France, S.; Mejiá-Oneto, J. M.; Padwa, A. Org. Lett. 2006, 8, 5141-5144.

https://doi.org/10.1021/ol062029z

54. Hong, X.; France, S.; Padwa, A. Tetrahedron 2007, 63, 5962-5976.

https://doi.org/10.1016/i.tet.2007.01.064

55. England, D. B.; Padwa, A. Org. Lett. 2007, 9, 3249-3252. 
https://doi.org/10.1021/ol071173x

56. England, D. B.; Padwa, A. J. Org. Chem. 2008, 73, 2792-2802.

https://doi.org/10.1021/j08001003

57. Wilkie, G. D.; Elliott, G. I.; Blagg, B. S. J.; Wolkenberg, S. E.; Soenen, D. R.; Miller, M. M.; Pollack, S.; Boger, D. L. J. Am. Chem. Soc. 2002, 124, 11292-11294.

https://doi.org/10.1021/ja027533n

58. Choi, Y.; Ishikawa, H.; Velcicky, J.; Elliott, G. I.; Miller, M. M.; Boger, D. L. Org. Lett. 2005, 7, 4539-4542. https://doi.org/10.1021/ol051975x

59. Elliott, G. I.; Velcicky, J.; Ishikawa, H.; Li, Y. K.; Boger, D. L. Angew. Chem. Int. Ed. 2006, 45, 620-622. https://doi.org/10.1002/anie.200503024

60. Ishikawa, H.; Elliott, G. I.; Velcicky, J.; Choi, Y.; Boger, D. L. J. Am. Chem. Soc. 2006, 128, 10596-10612. https://doi.org/10.1021/ja061256t

61. Ishikawa, H.; Colby, D. A.; Seto, S.; Va, P.; Tam, A.; Kakei, H.; Rayl, T. J.; Hwang, I.; Boger, D. L. J. Am. Chem. Soc. 2009, 131, 4904-4916.

https://doi.org/10.1021/ja809842b

\section{Author's Biography}

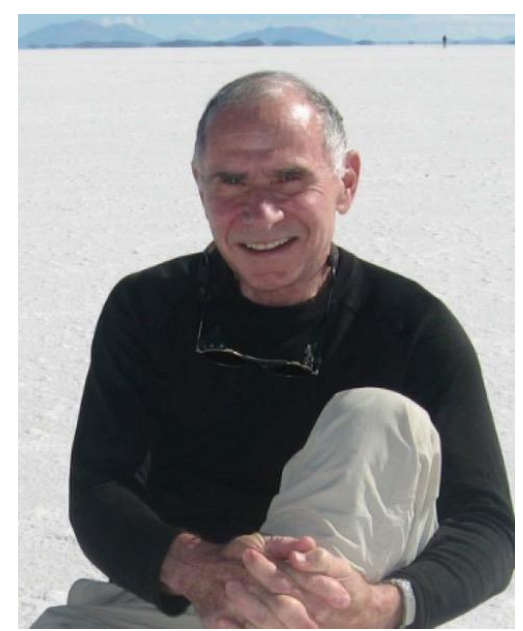

Albert Padwa was born in New York City. He received both his B.A. and Ph.D. degrees from Columbia University, the latter for graduate research work conducted with Cheves Walling in free radical chemistry. Following an NSF postdoctoral position at the University of Wisconsin with Howard Zimmerman, he was appointed as an Assistant Professor of Chemistry at the Ohio State University in 1963. He moved to SUNY Buffalo in 1966 as Associate Professor and was promoted to Professor in 1969. Since 1979, he was appointed the William Patterson Timmie Professor of Chemistry at Emory University. He has held visiting positions at the Swiss Federal Institute (ETH), University Claude Bernard France, Harvard University, the University of California at Berkeley, the University of Wurzburg Germany, Imperial College London U.K., and University of Melbourne Australia. As documented in over 725 publications, Prof. Padwa's research interests are diverse and have encompassed heterocyclic chemistry, dipolar cycloadditions, alkaloid synthesis, tandem transformations, organometallic chemistry, and organic photochemistry. Among other awards, Prof. Padwa has been the recipient of an Alfred P. Sloan Fellowship (1968-1970), a John S. Guggenheim Fellowship (1981-1983), an Alexander von Humboldt Senior Scientist Award (1983-1985), a Senior Award in Heterocyclic Chemistry from the International Society of Heterocyclic Chemists (1999), and an ACS Arthur C. Cope Scholar Award (2000). He 
served as the Chairman of the Organic Division of the ACS (1985-1986) and as President of the International Society of Heterocyclic Chemistry (1994-1996). He was an Associate Editor for the Journal of Organic Chemistry for 15 years and is currently one of the editors for Organic Reactions.

This paper is an open access article distributed under the terms of the Creative Commons Attribution (CC BY) license (http://creativecommons.org/licenses/by/4.0/) 